\title{
Prevalence and impact of cardiovascular metabolic diseases on COVID-19 in China
}

\author{
Bo Li ${ }^{1}$ (I) Jing Yang ${ }^{1,2} \cdot$ Faming Zhao ${ }^{3} \cdot$ Lili Zhi $^{4} \cdot$ Xiqian Wang ${ }^{1} \cdot$ Lin Liu $^{1} \cdot$ Zhaohui Bi $^{1} \cdot$ Yunhe Zhao ${ }^{1}$
}

Received: 17 February 2020 / Accepted: 2 March 2020 / Published online: 11 March 2020

c) Springer-Verlag GmbH Germany, part of Springer Nature 2020

\begin{abstract}
Background Studies have reminded that cardiovascular metabolic comorbidities made patients more susceptible to suffer 2019 novel corona virus (2019-nCoV) disease (COVID-19), and exacerbated the infection. The aim of this analysis is to determine the association of cardiovascular metabolic diseases with the development of COVID-19.

Methods A meta-analysis of eligible studies that summarized the prevalence of cardiovascular metabolic diseases in COVID19 and compared the incidences of the comorbidities in ICU/severe and non-ICU/severe patients was performed. Embase and PubMed were searched for relevant studies.

Results A total of six studies with 1527 patients were included in this analysis. The proportions of hypertension, cardiacerebrovascular disease and diabetes in patients with COVID-19 were $17.1 \%, 16.4 \%$ and $9.7 \%$, respectively. The incidences of hypertension, cardia-cerebrovascular diseases and diabetes were about twofolds, threefolds and twofolds, respectively, higher in ICU/severe cases than in their non-ICU/severe counterparts. At least 8.0\% patients with COVID-19 suffered the acute cardiac injury. The incidence of acute cardiac injury was about 13 folds higher in ICU/severe patients compared with the non-ICU/severe patients.

Conclusion Patients with previous cardiovascular metabolic diseases may face a greater risk of developing into the severe condition and the comorbidities can also greatly affect the prognosis of the COVID-19. On the other hand, COVID-19 can, in turn, aggravate the damage to the heart.
\end{abstract}

Keywords COVID-19 · 2019-nCoV · Cardiovascular metabolic diseases · Cardiac injury

\section{Introduction}

Bo Li and Jing Yang contributed equally to this article.

Bo Li

libosubmit@163.com

Yunhe Zhao

zhaoyunhe@medmail.com.cn

1 Department of Cardiology, Zibo Central Hospital, Shandong University, No. 10, Sonth Shanghai Road, Zibo 255000, People's Republic of China

2 Binzhou Medical University, No. 346, Guanhai Road, Laishan District, Yantai 264003, Shandong, People's Republic of China

3 Department of Infectious Diseases, No. 4 Hospital of Zibo, No. 210, Shan Quan Road, Zibo 255000, People's Republic of China

4 Department of Allergy, Zibo Central Hospital, Shandong University, No. 10, Sonth Shanghai Road, Zibo 255000, People's Republic of China
During the past two decades, the outbreak and prevalence of severe acute respiratory infections have been seen as one of the most serious hazards to global health. Both two prominent coronaviruses, 2002 SARS-CoV and 2012 MERS-CoV, have markedly affected humans, causing 8422 and 1600 infections, as well as 916 and 574 deaths, respectively [1,2].

In early December 2019, a series of pneumonia cases with unknown reason emerged in Wuhan, Hubei, China. Highthroughput sequencing from lower respiratory tract samples has revealed a novel coronavirus that was named 2019 novel coronavirus (2019-nCoV) and also named SARS-CoV-2 [3]. As of February 17th, 2020, 70,636 confirmed cases and 1772 death cases have been documented in China. 2019$\mathrm{nCoV}$ also targets the respiratory tract and shares many similar clinical symptoms with SARS-CoV and MERS-CoV [3]. Common symptoms include fever, fatigue, and dry cough, followed always by anorexia, myalgia, dyspnea, and so on 
[4-8]. Lymphopenia and prolonged prothrombin time are also the most common characteristics [4-6].

In addition, as cardiologists, we are also concerned about whether patients with cardiovascular disease are at greater risk for 2019-nCoV, and whether new coronavirus infections have an impact on the cardiovascular system. Previous studies have shown a relationship between cardiovascular metabolic diseases and SARS and MERS [9-11]. A systematic analysis of 637 MERS-CoV cases showed that diabetes and hypertension are prevalent in about $50 \%$ of the patients and cardiac diseases are present in $30 \%$ of the cases [11]. Diabetes was seen as an independent predictor for mortality and morbidity in patients with SARS [9]. With the spread of 2019-nCoV and increase of the cases, more and more 2019$\mathrm{nCoV}$ infected individuals exhibit comorbidities such as hypertension, diabetes and cardia-cerebrovascular disease. In Chen's study of 99 cases, $40 \%$ patients had cardia-cerebrovascular disease [6], and in Huang's study of 41 cases, $20 \%$ patients had diabetes [4]. These cardiovascular metabolic comorbidities might render them more susceptible to poor prognosis. Given the rapid spread of 2019-nCoV, an updated meta-analysis with significantly larger sample sizes by integrating the published studies is urgently warranted. Accordingly, the present analysis will not only identify the cardiovascular epidemiological and clinical characteristics of 2019-nCoV infection with greater precision but also unravel the impact of the infection on the cardiac injury.

\section{Methods}

Preferred Reporting Items for Systematic Reviews and MetaAnalyses of individual participant data (the PRISMA-IPD) statement was followed for the conduct and reporting of this meta-analysis [12].

\section{Data source, search strategy, and inclusion criteria}

To identify all the studies illustrating the prevalence and impact of cardiovascular metabolic diseases in 2019 novel coronavirus infection in China, EMBASE and PubMed were carefully searched from December 2019 to February 2020. The following search terms or keywords were used alone or in combination: 'novel coronavirus', 'influenza', 'pneumonia', 'cardiovascular disease', 'hypertension', 'diabetes' and 'cardiac injury'.

Inclusion criteria are as follows: (1) comparative studies: randomised controlled trials RCTs or non-RCTs published in English; (2) study population: more than ten participants were included in the study; (3) study intervention: patients in the studies should be confirmed to have been infected by 2019 novel coronavirus; (4) parameters: the comorbidities of cardiovascular metabolic diseases and the outcome of cardiac injury should be given. Case reports, non-human studies, studies without adequate information, and studies written in Chinese (for the fear of data duplication) were excluded in the present meta-analysis.

\section{Data extraction and study quality assessment}

Prevalence of comorbidities including hypertension, cardiovascular and cerebrovascular diseases and diabetes (Table 1 and Fig. 2) together with clinical outcome of cardiac injury (confirmed by elevation of Troponin I/T, or the creatine kinase seen as the second choice if Troponin $\mathrm{I} / \mathrm{T}$ were not provided) were extracted from the identified studies (Table 1 and Fig. 3). The primary outcome measure was to compare the prevalence of comorbidities and impact on cardiac injury in ICU and Non-ICU cases (severe and non-severe data as the second choice if ICU data was not provided). Cochrane Collaboration's tool was followed to assess the risk of bias.

\section{Data synthesis and statistical analysis}

All analyses were performed using OpenMeta Analyst version 10.10 (https://www.cebm.brown.edu/open_meta) and RevMan software version 5.3. Forest plots were used to illustrate the prevalence of the cardiovascular metabolic diseases in 2019-nCov infection severity from the selected studies as well as the impact of the 2019-nCov infection on the cardiac injury. The results of the included studies were performed with fixed-effect models (Mantel-Haenszel method) [13] or random-effect models in cases of significant heterogeneity between estimates [14]. We used the $\mathrm{I}^{2}$ statistics to assess the magnitude of heterogeneity: $25 \%, 50 \%$, and $75 \%$ represented low, moderate, and high degrees of heterogeneity, respectively. The chosen of the proper effect model was based on the analysis results: the fixed effect model was used if $I^{2}<50 \%$ and the random effect model was used if $I^{2} \geq 50 \%$ [15].

\section{Results}

\section{Selected studies and baseline characteristics}

After initially identifying 399 articles, 111 duplicate documents were identified. Of the leaving trials, after review of the titles and abstracts, 277 documents of non-human researches, reviews and studies that were not clinical trials were excluded. The leaving 11 studies were carefully 
Table 1 Number, age, sex and cardiovascular metabolic diseases of patients of the 6 included studies

\begin{tabular}{|c|c|c|c|c|c|c|c|c|c|}
\hline \multirow[t]{2}{*}{ References } & \multirow[t]{2}{*}{ Date } & \multirow{2}{*}{$\begin{array}{l}\text { Num- } \\
\text { ber of } \\
\text { patients }\end{array}$} & \multirow[t]{2}{*}{ Hospital } & \multirow[t]{2}{*}{ Age } & \multirow[t]{2}{*}{ Sex (male, \%) } & \multicolumn{4}{|c|}{ Cardiovascular metabolic diseases } \\
\hline & & & & & & $\begin{array}{l}\text { Hyper- } \\
\text { tension } \\
(\%)\end{array}$ & Diabetes $(\%)$ & $\begin{array}{l}\text { Cardia- } \\
\text { cerebrovascu- } \\
\text { lar disease }(\%)\end{array}$ & $\begin{array}{l}\text { Cardiac } \\
\text { injury } \\
(\%)\end{array}$ \\
\hline Wang et al. [5] & $\begin{array}{r}2020.01 .01- \\
2020.01 .28\end{array}$ & 138 & $\begin{array}{r}\text { Zhongnan } \\
\text { Hospital }\end{array}$ & $56(42-68)$ & 54.3 & 31.2 & 10.1 & 19.6 & 7.2 \\
\hline $\begin{array}{l}\text { Huang et al. } \\
\text { [4] }\end{array}$ & $\begin{array}{r}2019.12 .16- \\
2020.01 .02\end{array}$ & 41 & $\begin{array}{l}\text { Jinyintan } \\
\text { Hospital }\end{array}$ & $49(41-58)$ & 73 & 15 & 20 & 15 & 12 \\
\hline Guan et al. [8] & $\begin{array}{l}\text { As of } \\
2020.01 .29\end{array}$ & 1099 & $\begin{array}{l}552 \text { hospitals } \\
\text { in China }\end{array}$ & $47(35-58)$ & 59.2 & 14.9 & 7.4 & 3.9 & $13.7 *$ \\
\hline Chen et al. [6] & $\begin{array}{r}2020.01 .01- \\
2020.01 .28\end{array}$ & 99 & $\begin{array}{l}\text { Jinyintan } \\
\text { Hospital }\end{array}$ & $55.5(21-82)$ & 68 & - & 12 & 40 & $13^{*}$ \\
\hline $\begin{array}{l}\text { Chang et al. } \\
{[16]}\end{array}$ & $\begin{array}{r}2020.01 .16- \\
2020.02 .04\end{array}$ & 11 & $\begin{array}{l}3 \text { hospitals in } \\
\text { Beijing }\end{array}$ & $34(34-48)$ & 77 & - & - & - & - \\
\hline Liu et al. [17] & $\begin{array}{r}2019.12 .30- \\
2020.01 .24\end{array}$ & 137 & $\begin{array}{l}9 \text { tertiary } \\
\text { hospitals in } \\
\text { Hubei }\end{array}$ & $57(20-83)$ & 44.5 & 9.5 & 10.2 & 7.3 & - \\
\hline
\end{tabular}

In the two studies, 13(13\%) and 90 (13.7) patients were reported as elevation of creatine kinase, but they were not confirmed as cardiac injury

and detailed evaluated. At last, six studies were excluded, because the participants of the trials did not meet the criteria we have set. Then one study published in MedRxiv was added. Finally, a total of six studies with 1527 patients were included [4-6, 8, 16, 17] (Fig. 1). All of the selected studies were published in 2020 with different sample patient sizes that ranged from 11 to 1099 patients (Table 1 summarizes the study characteristics).

\section{Primary outcomes}

Systematic analysis of studies that described the epidemiological and clinical features of COVID-19 cases and reported the prevalence of cardiovascular metabolic diseases as well as the impact on cardiac injury in the infectious disease, has identified six reports with 1527 patients (Table 1). The majority of the cases were localized in Wuhan, or recent travel to Wuhan, or contact people from Wuhan. The median ages were, respectively, 56, 49, 47, 55.5, 34 and 57 years old according to the six studies. The infection was diagnosed throughout the whole spectrum of age covering from new born to 92 years old. In all of the studies, men were more likely to be infected than women and the overall proportion of male is $57.8 \%$.

Meta-analysis for the identified studies showed that the most prevalent cardiovascular metabolic comorbidities were hypertension $(17.1 \%, 95 \%$ CI 9.9-24.4\%) and cardia-cerebrovascular disease $(16.4 \%, 95 \%$ CI 6.6-26.1\%), followed by diabetes $(9.7 \%, 95 \%$ CI 6.9-12.5\%) (Fig. 2). There was a significant heterogeneity (Cochran's $Q$ ) in the estimates of comorbidities among the identified studies with an $I^{2}$ index varied from 47 to $95 \%$ (Fig. 2).

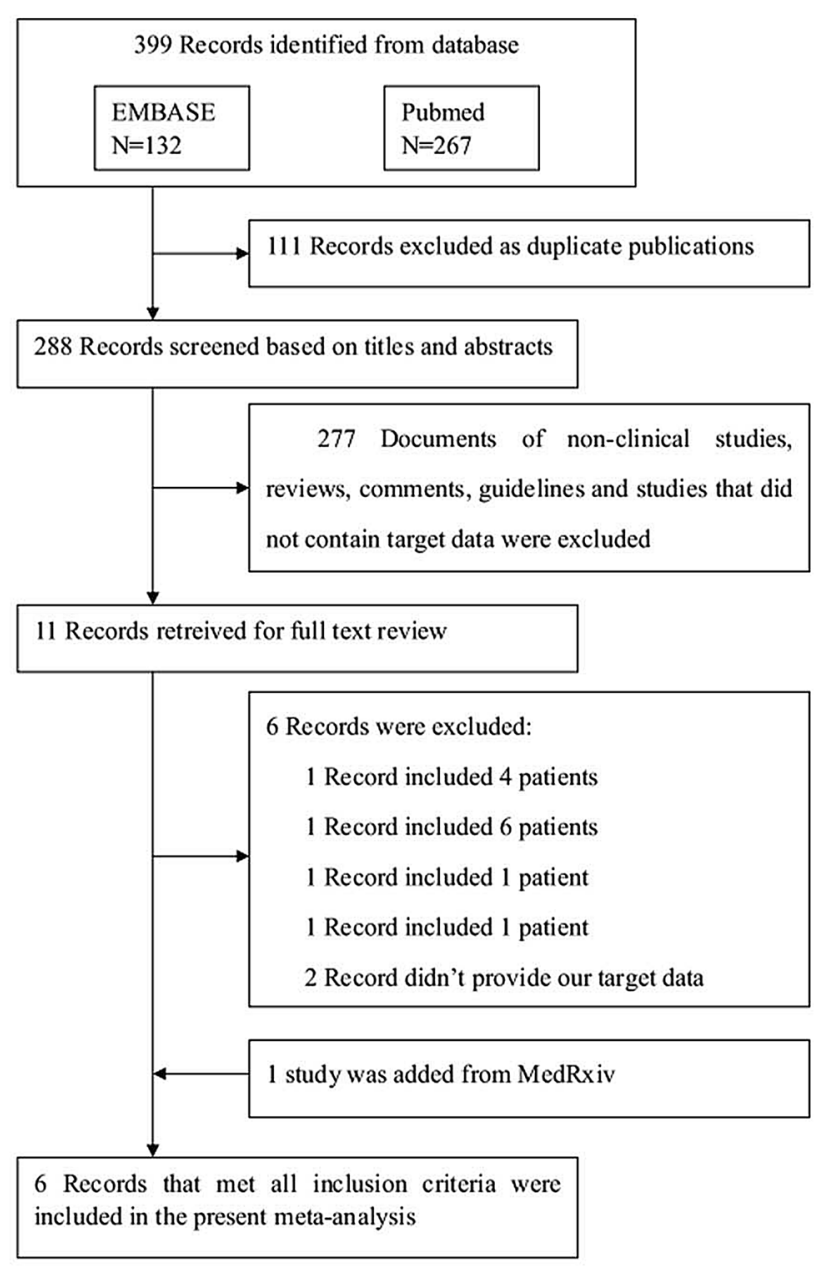

Fig. 1 Flow diagram of the study selection process 
A Hypertension

Studies

Estimate (95\% C.I.) Ev/Trt

Wang 20202020

Huang 20202020

Chen 20202020

$0.312(0.234,0.389) \quad 43 / 138$

$0.146(0.038,0.255) \quad 6 / 41$

$0.149(0.128,0.170) 164 / 1099$

$0.095(0.046,0.144) \quad 13 / 137$

Overall (I^2=86\%, P< 0.001) $0.171 \quad(0.099,0.244) \quad 226 / 1415$
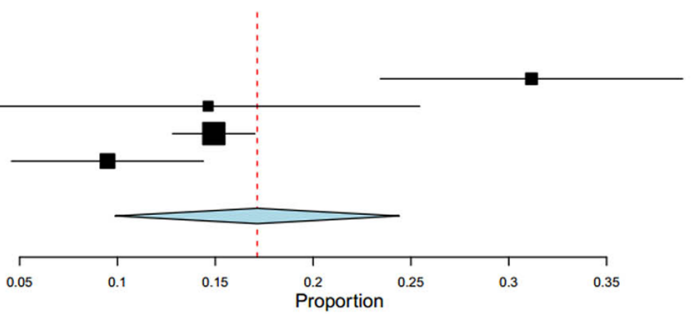

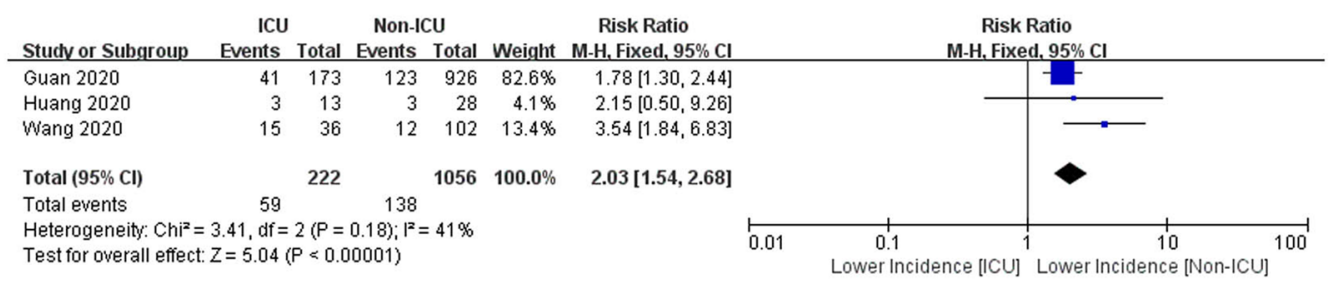

\section{B Cardia-cerebrovascular disease}

Studies

Wang 20202020

Huang 20202020

Guan 20202020

Chen 20202020

Liu 20202020

Overall $\left(\left.\right|^{\wedge} 2=95 \%, P<0.001\right) \quad 0.164 \quad(0.066,0.261) \quad 125 / 1514$
Estimate (95ะ C.I.) Ev/Trt

$0.196(0.129,0.262) \quad 27 / 138$

$0.146(0.038,0.255) \quad 6 / 41$

$0.404(0.307,0.501) \quad 40 / 99$

$0.038(0.027,0.050) \quad 42 / 1099$

$0.073(0.029,0.117) \quad 10 / 137$

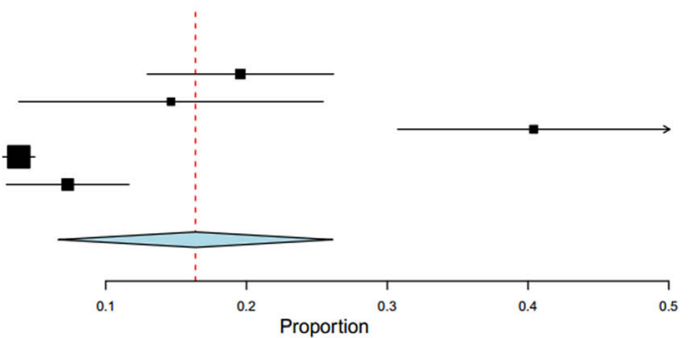

Odds Ratio

Odds Ratio

M-H. Fixed, $95 \%$ C

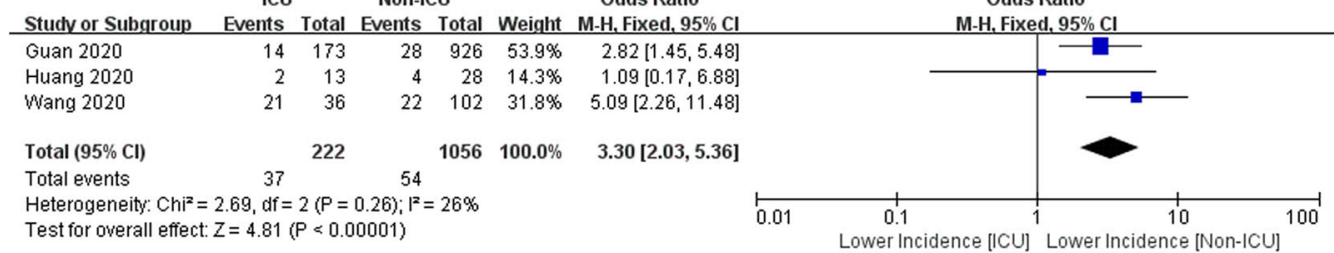

C Diabetes

Studies

Wang 20202020

Huang 20202020

Guan 20202020

Chen 20202020

Liu 20202020

Overall ( $\left(\left.\right|^{\wedge} 2=43 \%, P=0.133\right) \quad 0.097 \quad(0.069,0.125) \quad 129 / 1514$

Estimate (95: C.I.) Ev/Trt

$0.101(0.051,0.152) \quad 14 / 138$

$0.195(0.074,0.316) \quad 8 / 41$

$0.121(0.057,0.186) \quad 12 / 99$

$0.074(0.058,0.089) \quad 81 / 1099$

$0.102(0.051,0.153) \quad 14 / 137$ $\begin{array}{ccc} & \text { ICU Non-ICU } & \text { Risk Ratio } \\ \text { Studty or Subgroup Events } & \end{array}$

Studv or Subgroup Events Total Events Total Weight M-H.Random. 95\% Cl

$\begin{array}{lllllll}\text { Guan } 2020 & 28 & 173 & 53 & 926 & 50.2 \% & 2.83[1.84,4.34]\end{array}$

$\begin{array}{lrrrrrr}\text { Huang 2020 } & 1 & 13 & 7 & 28 & 15.6 \% & 0.31[0.04,2.25] \\ \text { Wang 2020 } & 8 & 36 & 6 & 102 & 34.2 \% & 3.78[1.41,10.15]\end{array}$

Total $(95 \% \mathrm{Cl})$

222

Total events $\quad 37 \quad 66 \quad \mathrm{Tau}^{2}=0.40 ; \mathrm{Chi}^{2}=5.27, \mathrm{df}=2(\mathrm{P}=0.07) ; \mathrm{i}^{2}=62 \%$

Total events
Heterogeneity: $\mathrm{Tau}^{2}=0.40 ; \mathrm{Chi}^{2}=5.27, \mathrm{df}=2(P=0.07) ; \mathrm{I}^{2}=62 \%$

$1056100.0 \%$

Test for overall effect: $Z=1.68(P=0.09)$

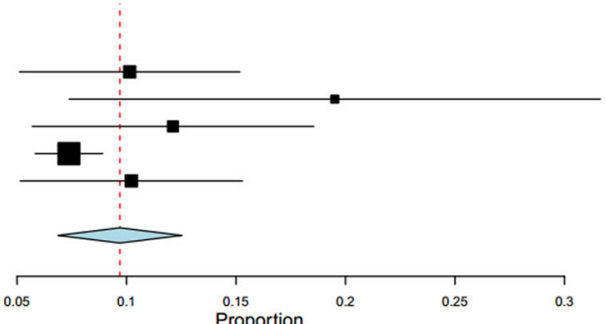

Risk Ratio $3.78[1.41,10.15]$

$2.21[0.88,5.57]$

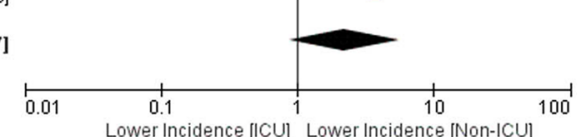


4Fig. 2 Meta-analysis for the proportion of hypertension, cardia-cerebrovascular disease and diabetes in COVID-19 cases. Weights are calculated from binary random-effects model analysis. Values represent proportions of the 3 diseases in the COVID-19 patients and $95 \%$ CI. Heterogeneity analysis was carried out using $Q$ test, the among studies variation $\left(I^{2}\right.$ index). Forest plots depict the comparison of the incidences of the 3 diseases in ICU/severe and non-ICU/severe patients

We then compared the difference of the prevalence of the three diseases between severe patients and non-severe patients (or ICU patients vs non-ICU patients according to the data in the studies). For hypertension and cardia-cerebrovascular disease, the heterogeneity test results were calculated as $I^{2}=47 \%$ and $26 \%$. Thus, the fixed-effect model was used for further analyses. The results from the three included studies (with a total amount of 1278 patients) showed that hypertension accounted for $28.8 \%$ of ICU/ severe cases, but $14.1 \%$ of non-ICU/severe cases. A similar pattern was found in cardia-cerebrovascular disease statistics: it accounted for $16.7 \%$ of ICU/severe cases, but $6.2 \%$ of non-ICU/severe cases. The proportion hypertension and cardia-cerebrovascular disease were both statistically significant higher in ICU/severe patients compared to the non-ICU/severe patients [hypertension: $\mathrm{RR}=2.03$, 95\% CI $(1.54,2.68), Z=5.04, P<0.00001$; cardia-cerebrovascular disease: $\mathrm{RR}=3.30,95 \% \mathrm{CI}(2.03,5.36), Z=4.81$, $P<0.00001$ ] (Fig. 2). For diabetes, the heterogeneity test showed that $I^{2}=67 \%$, and so the random effect model was used. Diabetes accounted for $11.7 \%$ of ICU/severe cases, but $4.0 \%$ of non-ICU/severe cases. The result indicated a higher proportion of diabetes in ICU/severe patients but without statistical significance $[R R=2.21,95 \%$ CI $(0.88$, 5.57), $Z=1.68, P=0.09$ ] (Fig. 2).

At last, we focused on the impact of the COVID-19 on the cardiac injury. Two studies that gave clear data were statistically analyzed, and the data showed that $8.0 \%$ (95\% CI 4.1-12.0\%) patients might be suffered from an acute cardiac injury. Another two studies only gave the data of creatine kinase, if it can be seen as a biomarker of cardiac injury, the proportion might be $11.5 \%$ (95\% CI 7.8-15.2\%). When we attempted to compare the differences of cardiac injury incidences between ICU/severe patients and non-ICU/severe patients, we just included the two studies which specifically identified myocardial injury. The data again showed a significant higher incidence of acute cardiac injury in ICU/severe patients compared to the non-ICU/severe patients $[\mathrm{RR}=13.48,95 \% \mathrm{CI}$ (3.60, 50.47), $Z=3.86, P=0.0001$ ] (Fig. 3). The funnel plots demonstrated symmetrical distributions of the effect size of hypertension, cardia-cerebrovascular diseases and cardiac injury on either side of the pooled estimate, but a non-symmetrical distribution of the effect size of diabetes (Fig. 4).

\section{Discussion}

Coronaviruses are enveloped RNA viruses, which include six species that can cause diseases in humans to our knowledge [18]. Four viruses among them (229E, OC43, NL63, and HKU1) have been reported to cause common cold symptoms in immunocompetent individuals [18]. However, the two other strains are the infamous SARS-CoV and MERS-CoV, which have been linked to fatal illness and caused plagues and large numbers of deaths [19]. Complete genome sequences of 2019-nCoV showed that it is identified as a novel betacoronavirus belonging to the sarbecovirus subgenus of Coronaviridae family, the same subgenus with SARS-CoV [3].

According to previous research on SARS-CoV, the presence of comorbidities increased the mortality risk, with cardiac disease and diabetes being the most important components to predict adverse outcomes [20]. Cardiac disease and diabetes increase the risk of death by twice as much as other risk factors [20]. Thus, it is necessary for us to evaluate the prevalence of cardiac and metabolic diseases in COVID-19. The present systematic analysis summarized the data from all of the five studies of COVID-19. The results demonstrated that the overall proportion of hypertension, cardia-cerebrovascular disease and diabetes were, respectively, $17.1 \%, 16.4 \%$ and $9.7 \%$. According to Summary of the 2018 report on cardiovascular diseases in China, the morbidities of the hypertension and diabetes were, respectively, $23.2 \%$ and $10.9 \%$, and there were about 13 million of cerebrovascular disease patients and 11 million of cardiovascular patients [21]. Therefore, comparing the data to the report, we did not find that people with hypertension and diabetes were more susceptible to 2019-nCoV infection. The prevalence of hypertension and diabetes in people infected with the virus is about the same as in the general population, even slightly lower. However, comparing the general population, the incidence of cardia-cerebrovascular disease in patients with COVID-19 is obviously much higher.

Due to the sample size and limited time so far, data collection is still incomplete, and most of the studies have not analyzed comorbidities in death cases. So the relationship between cardiovascular metabolic diseases and COVID19-induced death cannot be determined. But what is assuredly is that patients with hypertension, cardia-cerebrovascular diseases or diabetes are more likely to develop severe/ICU cases after 2019-nCoV infection. The overall proportion of hypertension, cardia-cerebrovascular diseases and diabetes were about twofolds, threefolds and twofolds, respectively, higher in ICU/severe cases than in their non-ICU/severe counterparts. Although the difference of diseases in the meta-analysis is not statistical, 

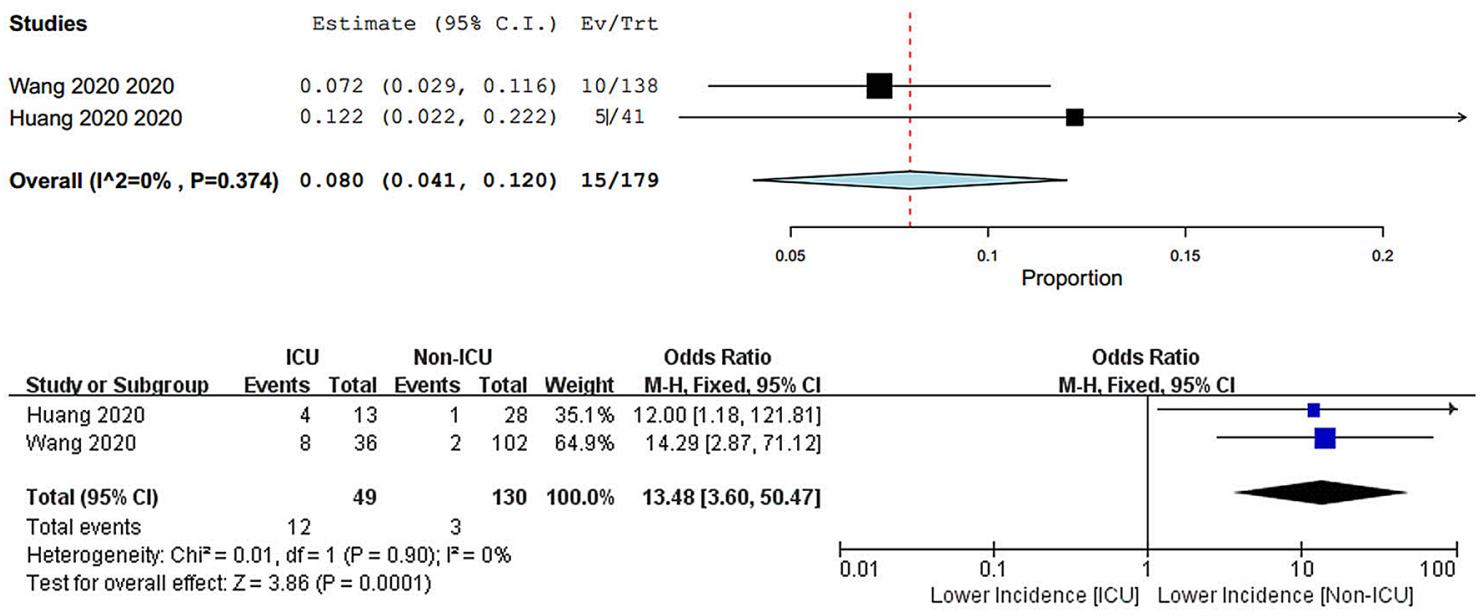

Fig. 3 Meta-analysis for the incidence of cardiac injury in COVID19 cases. Weights are calculated from binary random-effects model analysis. Values represent proportions of the cardiac injury in the COVID-19 patients and 95\% CI. Heterogeneity analysis was carried out using $Q$ test, the among studies variation ( $I^{2}$ index $)$. Forest plots depict the comparison of the incidences of cardiac injury in ICU/ severe and non-ICU/severe patients

\section{A Hypertension}

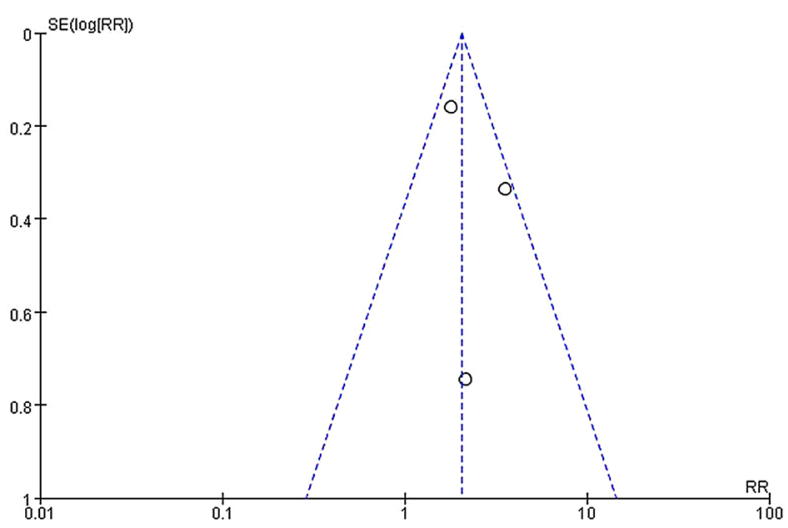

\section{Diabetes}

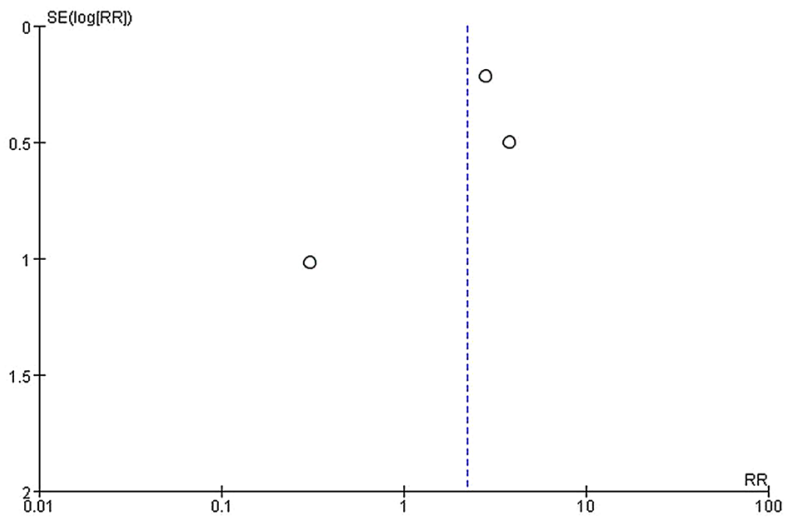

\section{B Cardia-cerebrovascular Disease}

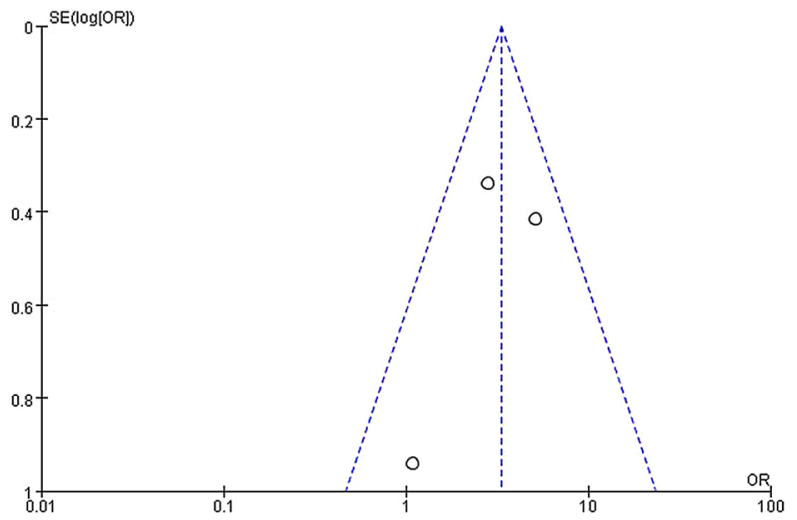

\section{Acute Cardiac Injury}

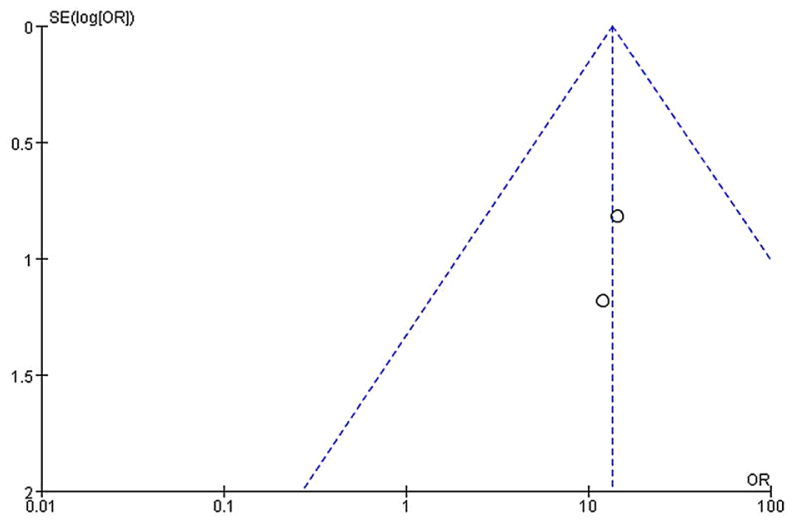

Fig. 4 Funnel plots of the comparisons of hypertension, cardia-cerebrovascular disease, diabetes and acute cardiac injury between ICU/severe and non-ICU/severe patients 
the RR value is about 2.21, and we consider this might because of the sample size of included studies and the algorithm adopts the random effect model which is a more conservative approach. So we speculate the result might reach statistical significance when more researches publish their data.

Another important finding is the damage the virus did to the heart. According to the present summary, at least $8.0 \%$ patients with COVID-19 suffered acute cardiac injury. In Chen's report, the first death was a 61-year old man with no previous chronic underlying disease. After he was admitted by ICU, he had developed severe respiratory failure, heart failure, and sepsis, and then experienced a sudden cardiac arrest on the 11th day of admission and was declared dead [6]. This case reminded us that patients with a novel coronavirus might develop acute cardiac injury. And further analysis indicates us that the incidence of myocardial injury is much higher in ICU/severe patients, about 13 folds more than non-ICU/cardiac patients. And furthermore, the observation also reminded us that patients with COVID-19 associated with unstable angina or STEMI have poor cardiac reserve, lower tolerance to severe pneumonia, and are more likely to develop cardiac insufficiency, leading to deterioration. According to the information released by Shanghai health commission, the first COVID-19 death in Shanghai was a patient 88 years old, with a serious history of hypertension, cardiac dysfunction. The analysis of death causes suggested that the patient died of heart failure and systemic multiple organ dysfunction, and in the course of its onset, the $2019 \mathrm{nCoV}$ infection is only the inducement.

The pathogenesis of $2019 \mathrm{nCoV}$ infection-related acute myocardial injury is still unknown. But according to the clinical presentation and lab data of the disease, as well as the pathogenesis of SARS-CoV, It can be speculated that 2019-ncov infection may affect the cardiovascular system through multiple mechanisms.

First, viral infection directly causes damage to cardiomyocyte. According to Oudit's study, SARS-CoV viral RNA was detected in $35 \%$ of autopsied human heart samples from SARS-CoV infected patients during the Toronto SARS outbreak [22]. And they also confirmed that pulmonary infection with the human SARS-CoV in mice led to an ACE2dependent myocardial infection [22]. ACE2 is an important target for SARS-CoV [23], and molecular modelling has shown high structural similarity between the receptor-binding domains of SARS-CoV and 2019-nCoV [24]. ACE2 expression is highly tissue-specific, mainly expressed in the cardiovascular, renal and gastrointestinal systems, with a small amount expressed in lung cells. Therefore, in addition to coronaviruses causing pneumonia through ACE2 receptors in lung epithelial cells, we also need to pay attention to possible viral effects on myocardial tissue. Second, hypoxaemia may be also an important reason of cardiac injury. In Huang's study, 32\% COVID-19 patients had various degree of hypoxaemia and need required high-flow nasal cannula or higher-level oxygen support. In Chen's study, up to $76 \%$ of patients require oxygen therapy. Due to severe 2019-nCoV infection, the pneumonia may cause significant gas exchange obstruction, leading to hypoxaemia, which significantly reduces the energy supply by cell metabolism, and increases anaerobic fermentation, causing intracellular acidosis and oxygen free radicals to destroy the phospholipid layer of cell membrane. Meanwhile, hypoxia-induced influx of calcium ions also leads to injury and apoptosis of cardiomyocytes. Third, Huang's study noted that high concentration of IL- $1 \beta$, IFN- $\gamma$, IP-10 and MCP- 1 could be detected in patients infected with 2019-nCoV, which might lead to activated T-helper-1 (Th1) cell responses [4]. Furthermore, they also found that ICU patients had much higher concentrations of inflammatory factors than those non-ICU patients, suggesting that the cytokine storm was associated with disease severity [4]. In addition, repeated floods of catecholamines due to anxiety and the side effects of medication can also lead to myocardial damage.

In conclusion, patients with previous cardiovascular metabolic diseases may face a greater risk of infection of 2019-nCoV and it can also greatly affect the development and prognosis of pneumonia. Simultaneously, we should pay close attention to viral infection-related heart damage in the course of disease treatment.

Funding This study was supported by the Natural Science Foundation of China (no. 81700321), the Key Research and Development Plan of Shandong Province (2018GSF118140).

\section{Compliance with ethical standards}

Conflict of interest None declared.

\section{References}

1. Chan KS, Zheng JP, Mok YW, Li YM, Liu YN, Chu CM, Ip MS (2003) SARS: prognosis, outcome and sequelae. Respirology 8(Suppl):S36-40

2. Badawi A, Ryoo SG (2016) Prevalence of diabetes in the 2009 influenza A (H1N1) and the middle east respiratory syndrome coronavirus: a systematic review and meta-analysis. J Public Health Res 5:733

3. Zhu N, Zhang D, Wang W, Li X, Yang B, Song J, Zhao X, Huang B, Shi W, Lu R et al (2020) A novel coronavirus from patients with pneumonia in China, 2019. N Engl J Med.

4. Huang C, Wang Y, Li X, Ren L, Zhao J, Hu Y, Zhang L, Fan G, $\mathrm{Xu}$ J, Gu X et al (2020) Clinical features of patients infected with 2019 novel coronavirus in Wuhan, China. Lancet

5. Wang D, Hu B, Hu C, Zhu F, Liu X, Zhang J, Wang B, Xiang H, Cheng Z, Xiong Y et al (2020) Clinical characteristics of 138 hospitalized patients with 2019 novel coronavirus-infected pneumonia in Wuhan, China. JAMA 
6. Chen N, Zhou M, Dong X, Qu J, Gong F, Han Y, Qiu Y, Wang J, Liu Y, Wei Y et al (2020) Epidemiological and clinical characteristics of 99 cases of 2019 novel coronavirus pneumonia in Wuhan, China: a descriptive study. Lancet

7. Hui DS, Azhar EI, Madani TA, Ntoumi F, Kock R, Dar O, Ippolito G, McHugh TD, Memish ZA, Drosten C et al (2020) The continuing 2019-nCoV epidemic threat of novel coronaviruses to global health-the latest 2019 novel coronavirus outbreak in Wuhan. China. Int J Infect Dis 91:264-266

8. Guan W-J, Ni Z-Y, Hu Y, Liang W-H, Ou C-Q, He J-X, Liu L, Shan H, Lei C-L, Hui DS et al (2020) Clinical characteristics of 2019 novel coronavirus infection in China. medRxiv: 2020.02.06.20020974

9. Yang JK, Feng Y, Yuan MY, Yuan SY, Fu HJ, Wu BY, Sun GZ, Yang GR, Zhang XL, Wang L et al (2006) Plasma glucose levels and diabetes are independent predictors for mortality and morbidity in patients with SARS. Diabet Med 23:623-628

10. Yu CM, Wong RS, Wu EB, Kong SL, Wong J, Yip GW, Soo YO, Chiu ML, Chan YS, Hui D et al (2006) Cardiovascular complications of severe acute respiratory syndrome. Postgrad Med J 82:140-144

11. Badawi A, Ryoo SG (2016) Prevalence of comorbidities in the Middle East respiratory syndrome coronavirus (MERS-CoV): a systematic review and meta-analysis. Int J Infect Dis 49:129-133

12. Stewart LA, Clarke M, Rovers M, Riley RD, Simmonds M, Stewart G, Tierney JF (2015) Preferred reporting items for systematic review and meta-analyses of individual participant data: the PRISMA-IPD statement. JAMA 313:1657-1665

13. Greenland S (1987) Quantitative methods in the review of epidemiologic literature. Epidemiol Rev 9:1-30

14. DerSimonian R, Laird N (1986) Meta-analysis in clinical trials. Control Clin Trials 7:177-188

15. Zhang Z, Wu P, Zhang J, Wang S, Zhang G (2016) The effect of statins on microalbuminuria, proteinuria, progression of kidney function, and all-cause mortality in patients with non-end stage chronic kidney disease: a meta-analysis. Pharmacol Res 105:74-83

16. Chang AU, Lin M, Wei L, Xie L, Zhu G, Dela Cruz CS, Sharma L (2020) Epidemiologic and clinical characteristics of novel coronavirus infections involving 13 patients outside Wuhan, China. JAMA

17. Liu K, Fang YY, Deng Y, Liu W, Wang MF, Ma JP, Xiao W, Wang YN, Zhong MH, Li CH, Li GC, Liu HG (2020) Clinical characteristics of novel coronavirus cases in tertiary hospitals in Hubei Province. Chin Med J (Engl). https://doi.org/10.1097/CM9.00000 00000000744

18. Su S, Wong G, Shi W, Liu J, Lai ACK, Zhou J, Liu W, Bi Y, Gao GF (2016) Epidemiology, genetic recombination, and pathogenesis of coronaviruses. Trends Microbiol 24:490-502

19. Cui J, Li F, Shi ZL (2019) Origin and evolution of pathogenic coronaviruses. Nat Rev Microbiol 17:181-192

20. Chan JW, Ng CK, Chan YH, Mok TY, Lee S, Chu SY, Law WL, Lee MP, Li PC (2003) Short term outcome and risk factors for adverse clinical outcomes in adults with severe acute respiratory syndrome (SARS). Thorax 58:686-689

21. Hu S, Gao R, Liu L, Zhu M, Wang W, Wang Y, Wu Z, Li H, Gu D, Yang Y (2019) Summary of the 2018 report on cardiovascular diseases in China. Chin Circ J 34:209

22. Oudit GY, Kassiri Z, Jiang C, Liu PP, Poutanen SM, Penninger JM, Butany J (2009) SARS-coronavirus modulation of myocardial ACE2 expression and inflammation in patients with SARS. Eur J Clin Invest 39:618-625

23. Li F, Li W, Farzan M, Harrison SC (2005) Structure of SARS coronavirus spike receptor-binding domain complexed with receptor. Science 309:1864-1868

24. Lu R, Zhao X, Li J, Niu P, Yang B, Wu H, Wang W, Song H, Huang B, Zhu N et al (2020) Genomic characterisation and epidemiology of 2019 novel coronavirus: implications for virus origins and receptor binding. Lancet 